\title{
ANÁLISIS DOGMÁTICO-PENAL DEL DELITO DE FINANCIAMIENTO DEL TERRORISMO
}

\author{
Juridical-dogmatic analysis of terrorism financing offenses
}

Ignacio Javier Plaza Chávez.

Resumen: Desde hace algunos años los expertos han estimado que una de las formas más eficaces para combatir el terrorismo consiste en entorpecer su financiación. Es a ello a lo que se ha avocado principalmente la Comunidad Internacional en el último tiempo.

Es por esta razón que en Chile tuvo lugar la dictación, en 2003, del artículo 8 de la Ley $\mathrm{N}^{\circ}$ 18.314, que vino a regular expresamente el delito de financiamiento del terrorismo. Posteriormente, ya en el 2009, la Ley No 20.393 hizo extensiva a las personas jurídicas la responsabilidad penal por la financiación de actividades terroristas.

Es el estudio de estas normas el objetivo de este trabajo, analizando desde el punto de vista dogmático-jurídico este delito, cuestión poco vista en la doctrina nacional, debido quizás a la reciente incorporación y escasa aplicación práctica que ha tenido este tipo penal.

Sin embargo, esto último no le resta importancia ni actualidad a este artículo, que se relaciona directamente con uno de los principales flagelos de nuestra época, el fenómeno del terrorismo, y con una de las formas más eficaces de prevenirlo, mediante la obstaculización de su financiamiento.

Palabras clave: legislación antiterrorista - artículo 8 Ley no 18.314 - financiamiento del terrorismo - análisis dogmático-jurídico - fuentes de financiamiento.

Abstract: For several years experts have thougth that one of the most effective ways to attack terrorism consists of obstructing its funding. This is one of the main topics considered by the International Communuty in the last time.

It is for this reason that in Chile took place the promulgation, in 2003, of the article 8 of the law $\mathrm{N}^{\circ} 18,314$, which expressly regulate the offenses related to terrorism financing. Later, in 2009 , the law $\mathrm{N}^{\circ} 20,393$ made the penal responsability extensive to legal persons for the financing of terrorist activities.

It is the aim of this paper to study these rules, analyzing this offense from a juridicaldogmatic point of view, usually unwatched by the national doctrine, maybe because of the recent incorporation and scarce practical application that has had this penal type.

However, the latter don't diminish the importance or actually to the paper, which is directly relates to one of the major scourages of our time, the phenomenon of the terrorism, and one of the most effective ways to prevent it, through the interference of his financing.

Keywords: anti-terrorist legislation - article 8 law $\mathrm{N}^{\circ} 18.314$ - terrorism financing juridical-dogmatic analysis - funding sources.

\footnotetext{
*Abogado. Correo electrónico: ignacioplara@outlook.com.
}

Este artículo fue recibido el 29 de junio de 2013, siendo aprobada su publicación el 23 de junio de 2014. 


\section{Introducción}

Los ataques sufridos por los Estados Unidos el 11 de septiembre de 2001 establecieron un antes y un después en lo que al terrorismo se refiere. Si bien los atentados de este tipo han estado presentes en nuestra historia desde tiempos inmemorables, luego de esta fecha es que han ido adquiriendo una mayor connotación a nivel mundial, principalmente debido al proceso de globalización que se vive actualmente.

Como consecuencia del mayor impacto de las actividades realizadas por este tipo de organizaciones, el fenómeno terrorista constituye hoy uno de los principales flagelos que golpea a todo el globo. Es por esta razón que se ha intentado combatirlo con una serie de medidas tendientes a atacarlo de la manera más eficaz posible. $Y$ es entre estas disposiciones que nos encontramos con todas aquellas normas relativas al financiamiento del terrorismo.

Esto, pues se ha estimado que una de las formas de lucha más eficaces contra el delito terrorista consiste en el establecimiento de trabas o entorpecimientos al proceso de financiación o entrega de aportes que se realiza a las organizaciones de esta índole, cuestión que dificultaría a estas la realización de sus diversas actividades.

A continuación procuraremos entregar un análisis lo más completo posible del delito de financiamiento del terrorismo desde su perspectiva dogmático-penal, abarcando desde este punto de vista un tema poco tratado en la doctrina nacional, debido, quizás, a su relativa nueva incorporación.

\section{Panorama general del delito de financiamiento del terrorismo}

El diccionario de la Real Academia Española define "financiamiento" como la "acción y efecto de financiar". Por su parte, "financiar" consiste en "aportar el dinero necesario para una empresa" o "sufragar los gastos de una actividad, de una obra, etcétera". De acuerdo con su sentido natural y obvio, debe entenderse por "sufragar", "ayudar o favorecer" o bien "costear, satisfacer".

Las definiciones recién transcritas parecieran indicar que el concepto de "financiamiento" se refiere únicamente a la entrega de una suma determinada de dinero. Sin embargo, y sin perjuicio de que en la mayoría de los casos se trate de dinero en efectivo, consideramos que en el ámbito jurídico y a propósito específicamente del terrorismo, de acuerdo tanto a los tratados internacionales como a las leyes internas que a ellos se remiten, el término "financiamiento" debe entenderse en un sentido más general, comprensivo no solo del aporte de montos de dinero, sino que de cualquier otro elemento que permita a los terroristas realizar los delitos que se propongan. 
Así se desprende del artículo 2 del Convenio Internacional para la Represión de la Financiación del Terrorismo que señala que "comete delito en el sentido del presente Convenio quien por el medio que fuere, directa o indirectamente, ilícita y deliberadamente, provea o recolecte fondos...". El artículo 1 del mismo tratado internacional indica en su número 1 que "por 'fondos' se entenderá los bienes de cualquier tipo, tangibles o intangibles, muebles o inmuebles, con independencia de cómo se hubieran obtenido, y los documentos o instrumentos legales, sea cual fuere su forma, incluida la forma electrónica o digital, que acrediten la propiedad u otros derechos sobre dichos bienes, incluidos, sin que la enumeración sea exhaustiva, créditos bancarios, cheques de viajero, cheques bancarios, giros, acciones, títulos, obligaciones, letras de cambio y cartas de crédito". ${ }^{\prime}$

Vale decir, de acuerdo con este tratado internacional, financia actividades terroristas no solo el que hace entrega de una cantidad líquida de efectivo, sino que también el que, por ejemplo, facilita algún título de crédito, quien suministra armamento o materiales para construirlo, el que pone a disposición un inmueble para que sirva como centro de operaciones, el que provee de medios de transporte o, más en general, aquel que proporciona cualquier elemento sin importar su especie, sea de origen lícito o ilícito, que sirva para la realización de alguno de los delitos que la propia Convención señala como terroristas.

Sin perjuicio de las diversas modalidades posibles y recalcando lo que dijimos con anterioridad, en la mayoría de los casos el aporte consistirá en dinero en efectivo. Ahora bien, y contrario a lo que podría pensarse, las organizaciones terroristas no requieren de grandes sumas para llevar a cabo sus propósitos, ya que cerca del 90\% del financiamiento se destina al mantenimiento general de las células y equipamientos, utilizándose solo el $10 \%$ para costear la ejecución de sus operaciones. Así lo afirma Louise Shelly, quien además señala que el verdadero problema se encuentra en hallar las fuentes de ayuda y respaldo al terrorismo. ${ }^{2}$

Esta financiación puede provenir de actividades tanto legítimas como ilegítimas. Dentro de las segundas, la más redituable la constituye el tráfico de drogas. Además se agrega a este catálogo el tráfico de personas, la falsificación de productos, los secuestros y la extorsión, entre otras. ${ }^{3}$ Las fuentes lícitas van desde emprendimientos comerciales a obras de caridad, siendo esta última una de las más importantes. Las importaciones y exportaciones y los casinos aportan fondos al terrorismo, del mismo modo como se usan para el lavado de dinero. ${ }^{4}$

\footnotetext{
${ }^{1}$ Convenio Internacional para la Represión de la Financiación del Terrorismo (2014).

2 SHELLY (2005), p. 1.

${ }^{3}$ Ibid., p. 2.

${ }^{4}$ Ibid., p. 3. A este respecto, debe señalarse que el delito de lavado de activos, también conocido como regularización, reconversión, naturalización o normalización de capitales es uno de los principales involucrados en el financiamiento del terrorismo. En ambos casos existe un abuso del sistema financiero. En el primero, este se utiliza para "blanquear" el producto de ciertas
} 
Ahora bien, con independencia de la especie, cantidad y origen de los fondos, en la actualidad el esfuerzo de la comunidad internacional se ha orientado en esta materia a la aprobación de leyes cuyo objeto ha sido la creación de un cuerpo normativo sólido que permita combatir el financiamiento del terrorismo. El mayor control ejercido sobre los clientes y los bancos ha sido central en la estrategia contra este delito. También ha sido de gran importancia la creación de unidades operativas para combatir el terrorismo. Entre las medidas que han sido más eficaces tenemos el congelamiento de las cuentas bancarias sospechosas, lo que ha impedido a los terroristas contar con la liquidez que necesitan. ${ }^{5}$

Ahora bien, sin perjuicio de su utilidad, estas medidas siguen siendo insuficientes, pues "los impedimentos más grandes para el seguimiento del financiamiento del terrorismo son la falta de entendimiento tanto público como profesional del financiamiento terrorista". Esta falta de comprensión del fenómeno se debe a que la inyección de fondos puede manifestarse de una gran variedad de formas, algunas muy elaboradas, y que se relacionan con muchos sectores de la comunidad financiera internacional, constituyendo un escenario complejo.

Lo anterior ha tenido como consecuencia la dictación de legislación, tanto a nivel nacional como internacional, que muchas veces no ha resultado ser congruente ni idónea para combatir esta problemática, constituyéndose esto en un impedimento muy grande en la persecución del delito. Es más, en ciertos casos ni siquiera se llega a los estándares mínimos de control requeridos a nivel internacional, siendo esto de radical importancia si se tiene en cuenta que el éxito del financiamiento se basa especialmente en su discreción e imposibilidad de rastreo.

actividades ilícitas, mientras que en el segundo es útil para transferir fondos a los terroristas y subsidiar sus actividades.

Mediante el lavado de dinero se busca dotar de licitud activos originados de un ilícito bajo cualquier tipo de modalidad o actividad (narcotráfico, venta ilegal de armas, juego clandestino, trata de blancas, prostitución, malversación de fondos públicos, uso malicioso de información privilegiada, cohecho, fraude informático, etcétera).

En Chile, el lavado de dinero encuentra actualmente su principal regulación en el artículo 27 de la Ley No 19.913, que creó la Unidad de Análisis Financiero. Esta última señala que este delito “implica introducir en la economía activos de procedencia ilícita, dándoles apariencia de legalidad al valerse de actividades lícitas, lo que permite a delincuentes y organizaciones criminales disfrazar el origen ilegal de su producto, sin poner en peligro su fuente".

En cuanto a la tipicidad de este delito y su similitud con el financiamiento del terrorismo, el principal parecido dice relación con el bien jurídico protegido, ya que, según Lastra López y Andueza Quezada, en el blanqueo de capitales este es de carácter dual y está conformado por la seguridad del Estado y la paz social, semejante a lo que ocurre, como se verá, con el delito de financiación.

Un análisis completo y detallado de los demás elementos del tipo penal del delito de blanqueo de capitales en LASTRA y ANDUEZA (2009).

5 Íbid., p. 7.

${ }^{6}$ Íbid., p. 8. 
Es así como estas importantes dificultades recién señaladas han tenido su manifestación en la legislación chilena, que se ha abocado a la regulación de la materia mediante diversos cuerpos normativos, tanto ordinarios como especiales, cayendo, sin embargo, y como se verá más adelante, en la inconsistencia que genera la falta de conocimiento acerca del tema.

El delito de financiamiento del terrorismo encuentra regulación expresa en Chile en dos cuerpos normativos, principalmente. ${ }^{7}$ El primero es el artículo 8 de la

\footnotetext{
7 Otras normas que se refieren al delito de financiamiento del terrorismo, pero de manera indirecta, son:
}

a) La Constitución Política de la República, además de constituir la fuente directa de la Ley No 18.314 al establecer la obligación de dictar una ley de quórum calificado para regular la materia (artículo 9 inciso 2), declara que "El terrorismo, en cualquiera de sus formas, es por esencia contrario a los derechos humanos" (inciso $1^{\circ}$ del citado artículo). Asimismo, la Constitución también señala algunas sanciones para los responsables de esta clase de delitos, tales como la pérdida de la ciudadanía, por ejemplo.

b) El Código Penal contiene en su Parte Especial algunas normas a las que la Ley № 18.314 hace expresa referencia en su artículo $2^{\circ}$, por tratarse de ciertos delitos que pueden servir de base a la conducta terrorista y cuya financiación se encuentra prohibida.

c) El Código Procesal Penal tiene plena aplicación en los procedimientos substanciados a propósito del delito de financiación del terrorismo, aunque con algunas modificaciones introducidas por la Ley № 18.314. Las dos más importantes consideramos que son las establecidas por los artículos 11 y 14 de la Ley Antiterrorista. El primero de ellos, a propósito de la detención, faculta al juez de garantía para ampliar hasta por diez días los plazos para poner al detenido a su disposición y para formalizar la investigación, siempre que las necesidades de la investigación así lo requieran, a solicitud del fiscal y por resolución fundada. Cabe recordar que el plazo máximo y excepcionalísimo que establece el Código Procesal Penal es de 3 días.

Por su parte, el artículo 14 de la Ley No 18.314 introduce ciertas medidas cautelares que el juez de garantía podrá decretar a solicitud del Ministerio Público, durante la audiencia de formalización o una vez formalizada esta, si procediere la prisión preventiva. Estas medidas consisten en recluir al imputado en lugares públicos especialmente destinados a este objeto, establecer restricciones al régimen de visitas, e interceptar, abrir o registrar sus comunicaciones telefónicas e informáticas y su correspondencia epistolar y telegráfica.

d) La Ley No 12.927, sobre seguridad del Estado, se relaciona con la Ley Antiterrorista fundamentalmente por los eventuales problemas concursales que podrían suscitarse entre ambos cuerpos normativos. Ello podría ocurrir, por ejemplo, en el caso del artículo 4 letra d) que sanciona a quienes participen en el financiamiento de bandas armadas, que tengan por objetivo alguno de los delitos señalados en la misma disposición. Esto es semejante a lo señalado en el artículo 8 de la Ley No 18.314, y podría generar concursos de leyes penales en la medida que no logre establecerse con claridad cuál es la finalidad detrás del delito. Iguales inconvenientes podrían suscitarse con los artículos 5 a), 5 b) y 6 .

e) La Ley No 17.798, que establece el control de armas, se vincula indirectamente con la Ley Antiterrorista, pues establece normas acerca de la posesión o tenencia de ciertas armas y elementos similares que, sin lugar a dudas, pueden ser utilizados en atentados de este tipo. Además, el artículo 8 prohíbe la organización, pertenencia, financiamiento, dotación, ayuda, instrucción o incitación a la creación y funcionamiento de milicias privadas, grupos de combate o partidas militarmente organizadas, armadas con elementos prohibidos, norma dentro de la cual podrían encuadrarse los grupos terroristas y sus financistas.

f) La ley No 19.913 crea la Unidad de Análisis Financiero, cuyo objeto es prevenir e impedir la utilización del sistema financiero y de otros sectores de la actividad económica para la comisión de alguno de los delitos descritos en el artículo 27 de la misma ley, que castiga al que de cualquier forma oculte o disimule el origen ilícito de determinados bienes, a sabiendas de que provienen, de 
Ley $\mathrm{N}^{\circ} 18.314$, que determina conductas terroristas y fija su penalidad, artículo introducido por la Ley $\mathrm{N}^{\circ} 19.906$, que modificó la Ley Antiterrorista en orden a sancionar de modo más eficaz la financiación del terrorismo, y que fue publicada en el Diario Oficial el 13 de noviembre de 2003.

En segundo lugar, este delito está regulado en la Ley $\mathrm{N}^{0}$ 20.393, que establece responsabilidad penal de las personas jurídicas en los delitos de lavado de activos, financiamiento del terrorismo y delitos de cohecho que indica, la que fue publicada el 2 de diciembre de 2009 como respuesta a ciertos compromisos internacionales adoptados por nuestro país.

Este último cuerpo legal especial viene a introducir una excepción al principio de Derecho penal que señala que "las sociedades no pueden delinquir" (societas delinquere non potest), en el sentido de que las personas jurídicas de Derecho privado y las empresas del Estado son, de acuerdo con esta ley, responsables penalmente de los delitos de lavado de activos, financiamiento del terrorismo y cohecho activo o soborno y aquel realizado a funcionario público extranjero, siempre y cuando estos ilícitos fueren cometidos de manera directa e inmediata en su interés o para su provecho, por sus dueños, controladores, responsables, ejecutivos principales, representantes o quienes realicen actividades de administración y supervisión, siempre que la comisión del delito fuere consecuencia del incumplimiento, por parte de esta, de los deberes de dirección y supervisión.

\section{Estudio dogmático-jurídico del delito de financiamiento del terrorismo}

Sin perjuicio de la innegable importancia de la Ley $\mathrm{N}^{\circ}$ 20.393, nuestro trabajo se desarrollará principalmente por medio del análisis del artículo 8 de la Ley $\mathrm{N}^{\circ} 18.314$, haciendo referencia a los preceptos de aquella solo en lo no regulado por esta.

\section{a. Norma fundamental relativa al financiamiento del terrorismo: artículo 8 de la Ley $\mathrm{N}^{\circ} 18.314$}

El Mensaje Presidencial que acompañó a la Ley $\mathrm{N}^{0}$ 19.906, que incorporó el artículo 8 de la Ley Antiterrorista, señala que, con anterioridad a su entrada en vigencia, el delito de financiamiento solo era penado bajo 2 hipótesis: ${ }^{8}$

manera directa o indirecta, de la perpetración de hechos constitutivos de alguno de los delitos contemplados en la Ley No 18.314; o bien, a sabiendas de dicho origen, oculte o disimule estos bienes.

g) La Ley No 20.000 sanciona el tráfico ilícito de estupefacientes y sustancias sicotrópicas, el cual constituye una de las principales fuentes de financiamiento de origen ilícito que tiene el terrorismo, debido a las grandes sumas de dinero que a propósito de esta actividad se manejan.

${ }^{8}$ Mensaje de S. E. el Presidente de la República de 2 de octubre de 2002. Historia de la Ley № 19.906, que modifica la Ley No 18.314, que determina conductas terroristas y fija su penalidad, en orden a sancionar más eficazmente la financiación del Terrorismo, en conformidad a lo dispuesto por el Convenio Internacional para la Represión de la Financiación del Terrorismo, p. 6. 
Primero, aparecía como punible en cuanto financiamiento de la ejecución de un delito terrorista determinado de aquellos previstos en el artículo 2 de la ley, conducta que podía castigarse como autoría o, al menos, como complicidad en el respectivo delito terrorista, según las circunstancias particulares del caso y de acuerdo con las reglas generales de participación contenidas en el Código Penal; y

Segundo, el financiamiento del terrorismo resultaba punible en cuanto provisión a una asociación ilícita terrorista. Por lo tanto se sancionaba al financista como partícipe del delito de asociación ilícita terrorista.

Así, la situación era precaria, pues solo se regulaban estos dos casos, excluyéndose otros, como ocurría, por ejemplo, con la provisión de fondos no vinculable a una asociación ilícita terrorista ni a delitos terroristas determinados. Además, en los dos supuestos de hecho regulados se requería de un financiamiento efectivo, esto es provisión o entrega real de fondos, no siendo punible, en principio, la mera recolección o recaudación previa, resultando, la normativa vigente en Chile, bastante escueta comparada con los tratados internacionales relativos a la materia.

Para soslayar estas dificultades se propuso el siguiente tipo penal basado en lo prescrito por el artículo 2 del Convenio:

"El que por cualquier medio, directa o indirectamente, recaude o provea fondos con la finalidad de que se utilicen en la comisión de delitos de los señalados en el artículo 2, será castigado con la pena de presidio menor en sus grados mínimo a medio, a menos que en virtud de la provisión de fondos le quepa responsabilidad en un delito determinado, caso en el cual sólo se le sancionará por este último título, sin perjuicio de lo dispuesto en el artículo 294 bis del Código Penal".

En el primer trámite constitucional, mediante informe de la Comisión de Constitución, Legislación y Justicia, la Honorable Cámara de Diputados eliminó la "cláusula de subsidiariedad expresa", a instancias del profesor y diputado en ese entonces, Juan Bustos Ramírez, por estimarla innecesaria en virtud de las reglas generales del Derecho penal y de la doctrina. ${ }^{10}$

En la discusión en Sala, en tanto, los diputados Jorge Burgos Varela, Marcelo Forni Lobos y Edgardo Riveros Marín plantearon la necesidad de

\footnotetext{
${ }^{9} \mathrm{El}$ proyecto original consideraba introducir este nuevo tipo penal en el inciso final del artículo 7 de la Ley No 18.314, que sanciona la tentativa y la conspiración de cometer delitos terroristas. Luego se pensó agregarlo como artículo 7 bis, pero finalmente se optó por hacerlo en reemplazo del derogado artículo 8. Historia de la Ley No 19.906, p. 7.

${ }^{10}$ Historia de la Ley No 19.906 , p. 18.
} 
introducir el verbo rector "solicite", anteponiéndolo a "recaude o provea". Ello por cuanto, según señalaron, era posible que quien recaudara no fuera el mismo que solicitara los fondos. ${ }^{11}$

Luego de las diversas etapas de discusión y trámites constitucionales, la primera moción fue rechazada y la segunda aprobada, quedando definitivamente la redacción del precepto de la siguiente manera:

El que por cualquier medio, directa o indirectamente, solicite, recaude o provea fondos con la finalidad de que se utilicen en la comisión de cualquiera de los delitos terroristas señalados en el artículo 2, será castigado con la pena de presidio menor en sus grados minimo a medio, a menos que en virtud de la provisión de fondos le quepa responsabilidad en un delito determinado, caso en el cual se le sancionará por este último título, sin perjuicio de lo dispuesto en el articulo 294 bis del Código Penal.

Este precepto, incorporado por la Ley $\mathrm{N}^{\circ} 19.906$, es el resultado directo de la suscripción por parte de Chile del Convenio Internacional para la Represión de la Financiación del Terrorismo en 2001 y de la dictación, por parte del Consejo de Seguridad de las Naciones Unidas, de la resolución $\mathrm{N}^{\circ} 1373$ el mismo año, emitida principalmente con motivo de los atentados terroristas ocurridos el 11 de septiembre de 2001 en Nueva York.

\section{b. Bien jurídico protegido en el delito de financiamiento del terrorismo}

El bien jurídico protegido constituye el objeto de tutela de la norma penal. No debe confundirse con el objeto material (cosa o persona sobre la que recae la acción), ya que este último concepto tiene un significado meramente natural y el de bien jurídico implica un contenido valorativo. Además, el bien jurídico nunca puede faltar, mientras que existen delitos que carecen de un objeto material, ${ }^{12}$ como ocurre, según nuestro parecer, en algunas hipótesis del financiamiento del terrorismo, pues, por tratarse de un delito de mera actividad o formal que no requiere más que la realización de la acción típica para que se consume, en ciertos casos el financiamiento del terrorismo se configurará aun cuando los fondos no puedan ser vinculados a la realización de una conducta terrorista concreta, en cuyo caso no habría objeto material.

$\mathrm{Al}$ efecto, el profesor Vivian Bullemore Gallardo sostiene que los delitos formales "se refieren a casos en que no existen objetos materiales del resultado y se trata más bien de bienes jurídicos inmateriales o intangibles". ${ }^{13}$ Esta afirmación nos parece correcta, sin perjuicio de que deba matizarse señalando que no se trata

\footnotetext{
${ }^{11}$ Historia de la Ley № 19.906, p. 26.

12 Politoff, Matus y Ramírez (2004), pp. 190-191.

${ }^{13}$ Bullemore (2005), p. 14.
} 
de una verdad absoluta, pues existen delitos de mera actividad que tienen un objeto material afectado.

Estaremos frente a la situación planteada por el profesor Bullemore Gallardo tratándose de los dos primeros verbos rectores de nuestro tipo penal, solicitar y recaudar, ya que en este caso no es necesario que los fondos sean efectivamente recibidos por el agente y entregados a otro para que se configure el tipo penal, en cuyo caso no habría objeto material del delito, pues, como se verá más adelante, solo se afectará bienes jurídicos de carácter colectivo e intangible.

En cambio, tendrá lugar un ilícito de mera actividad con objeto material dañado cuando la provisión de fondos se realice con miras a un delito terrorista específico que efectivamente se lleva a cabo. En esta hipótesis, el bien jurídico afectado tendrá carácter dual, pues se tratará, como enseguida explicaremos, de los bienes jurídicos colectivos y, además, de los bienes individuales de carácter material y concreto afectados directamente por el ilícito.

Ahora bien, tanto en el delito terrorista como en su financiación, el bien jurídico protegido es el mismo, pero se produce, en este último caso, una anticipación en la tutela. Así lo deja de manifiesto el mensaje presidencial cuando apunta que mediante un elemento subjetivo especial distinto del dolo (intención o finalidad de que los fondos proporcionados se utilicen para cometer delitos terroristas) "se desvincula el financiamiento de la efectiva realización de un delito terrorista específico, adelantándose la barrera de protección de los bienes jurídicos que pueden verse vulnerados por él". ${ }^{14}$

Si bien podría sostenerse, a propósito del financiamiento, que estamos en presencia de actos meramente preparatorios que no entran en la esfera de ejecución del delito y que, por tanto, no deberían ser punibles, nuestro legislador, atendida la importancia de determinados hechos, "anticipa la punición hasta alcanzar comportamientos que, por sí mismos, por su propia estructura y naturaleza, están alejados no solo de la lesión del bien jurídico, sino también de la idea de peligro concreto". ${ }^{15}$

La determinación del bien jurídico afectado por los delitos de terrorismo y su financiación no es un tema pacífico en doctrina. La confusión en torno a qué es lo que se pretende preservar impide al bien jurídico cumplir con su función garantizadora de carácter cognoscitivo, vale decir, no se sabe qué es lo que se resguarda, situación que va en detrimento del principio de legalidad. Por otra parte, esta indeterminación no permite al bien jurídico desarrollar su función crítica, esto es, por qué se protege un determinado interés. ${ }^{16}$

\footnotetext{
${ }^{14}$ Historia de la Ley No 19.906, p. 6.

${ }^{15}$ CAMPO (1997), p. 55.

16 Villegas (2001), p. 596.
} 
Sin perjuicio de la problemática en cuanto a su determinación, nosotros consideramos que el bien jurídico protegido en el delito de terrorismo y su financiación tiene un carácter dual:

En primer término, de los artículos 9 de la Constitución y 2 de la Ley $\mathrm{N}^{\circ}$ 18.314 se desprende que se trataría de bienes jurídicos individuales, específicamente, la vida, la integridad física y la libertad de las personas.

Esto lo confirma el propio mensaje presidencial de la Ley $\mathrm{N}^{\circ} 19.027$ que señala que "Lo que caracteriza la conducta terrorista es el atentar contra la vida, la integridad física o la libertad de las personas...". ${ }^{17}$

Se debe excluir, según nuestro parecer y el de Villegas Díaz, ${ }^{18}$ la propiedad o patrimonio, aun cuando la Ley $\mathrm{N}^{\circ} 18.314$ se refiera a ella en su artículo 2 número 4 (sancionando como terrorista el uso de bombas o artefactos explosivos o incendiarios que causen daños) y la Constitución la consagre como una garantía fundamental, pues este derecho ya se encuentra protegido adecuadamente por la legislación penal, tanto común como especial.

Esta última afirmación se fundamenta en el menor rango que tendría la propiedad frente a los otros derechos individuales protegidos, ya que el hecho de que se encuentre constitucionalmente resguardada no implica necesariamente que se trate de un derecho humano, como sí ocurre con los demás bienes individuales. Por lo mismo, resultaría contrario a los principios básicos del Derecho penal, especialmente al de ultima ratio, sancionar tan gravemente, mediante la legislación antiterrorista, el ataque a bienes cuya naturaleza de derecho humano resulta hoy cuestionable. ${ }^{19}$

Además, la propiedad es de aquellas necesidades humanas llamadas "alienadas", por lo que la utilidad de protegerla mediante este estatuto especial más grave resulta dudosa. ${ }^{20}$ No se opone a esto el numeral 4 del artículo 2 de la Ley Antiterrorista, ya que las acciones en él sancionadas pueden generar, por su alto poder destructivo, peligro de lesiones en los bienes jurídicos, vida, integridad física y libertad, como correlativo de la destrucción de la propiedad que se vea afectada por explosivos o bombas. Es por ello que, en este caso, la protección de la propiedad por medio de la Ley Antiterrorista se encontraría entonces justificada.

Por último, debe tenerse presente que el ataque a estos bienes jurídicos individuales será considerado como terrorista únicamente en la medida que el

\footnotetext{
${ }^{17}$ Historia de la Ley $\mathrm{N}^{\circ} 19.027$, que modifica la Ley $\mathrm{N}^{\circ} 18.314$, que determina conductas terroristas y fija su penalidad, p. 5 .

${ }^{18}$ ViLLEGAS (2001), p. 614.

${ }^{19}$ Ibid.

${ }^{20}$ Ibid.
} 
delito se cometa con la finalidad de lesionar otros bienes jurídicos colectivos de mayor entidad, pues en este caso "es la agresión a la convivencia pacífica de las personas asegurada por un cierto orden social lo que da fundamento al injusto". ${ }^{21}$ Por el contrario, cuando no exista esta última intención no nos encontraremos frente a un delito terrorista, sino que solo se tratará de un simple ilícito común.

En segundo lugar, de la lectura de los elementos subjetivos contenidos en el artículo 1 de la Ley $\mathrm{N}^{\circ} 18.314$ se desprende que la legislación antiterrorista también resguarda bienes jurídicos colectivos. $\mathrm{El} \mathrm{N}^{\circ} 1$ de dicho artículo establece que el delito será terrorista cuando se realice con la finalidad de intimidar a la población o a un sector de ella, por lo que podríamos señalar que lo que se trata de proteger es el bien jurídico "seguridad pública", que hace referencia a la tranquilidad, calma u orden de las calles y otros lugares públicos y que, según la doctrina, se define como "una razonable esperanza de no ser víctima de agresiones, y lleva inscrita un elemento espiritual, relativo al sosiego de amplios sectores de la población". ${ }^{22}$

Además, el $\mathrm{N}^{\circ} 2$ del artículo 1 exige, para que el delito sea terrorista, que sea cometido con el objeto de "arrancar resoluciones de la autoridad o imponerle exigencias", lo que se asemeja ciertamente a lo establecido en algunos tipos penales contenidos en la Ley $\mathrm{N}^{\mathrm{o}}$ 12.927. Por ello es posible establecer que lo que se está queriendo preservar es, asimismo, la "seguridad interior del Estado".

Resumiendo entonces, los delitos de terrorismo y su financiamiento, según la legislación vigente en nuestro país y de acuerdo con nuestra perspectiva, son pluriofensivos, vale decir, atacan bienes singulares (vida, integridad física y libertad, excluyéndose la propiedad) y colectivos (seguridad pública y seguridad interior del Estado).

\section{c. Tipicidad en el ilícito de financiación de actividades terroristas}

Todos los tipos penales tienen en común una estructura que responde a la necesidad de describir una conducta con un lenguaje corriente. A continuación analizaremos estos elementos detenidamente en lo que al delito de financiamiento del terrorismo se refiere.

\section{i. Los sujetos}

El sujeto activo, en el caso del delito que estamos analizando, es indiferenciado, ya que puede ser cometido por cualquier persona natural distinta de aquella que materialmente realiza los actos constitutivos de delito terrorista ("El que...", como parte señalando el artículo 8 de la Ley $\mathrm{N}^{\circ}$ 18.314).

\footnotetext{
${ }^{21}$ ViLLEGAS (2001), p. 569.

${ }^{22}$ Del Barrio (1991), p. 200.
} 
Estamos, por consiguiente, frente a un delito de los denominados comunes en atención al sujeto activo, ya que cualquiera puede serlo siempre y cuando cumpla, obviamente, con los requisitos generales de imputabilidad.

Además, serán sujetos activos aquellas personas jurídicas contempladas en la Ley $\mathrm{N}^{\circ}$ 20.393, es decir, aquellas de Derecho privado y empresas del Estado cuando el delito sea cometido directa e inmediatamente en su interés o para su provecho, por sus dueños, controladores, responsables, ejecutivos principales, representantes o quienes realicen actividades de administración y supervisión, o por las personas naturales que estén bajo la dirección o supervisión directa de alguno de esos sujetos, siempre que la comisión del delito fuere consecuencia del incumplimiento, por parte de la persona jurídica, de los deberes de dirección y supervisión.

Respecto del sujeto activo hay que tener presente la siguiente cuestión. Existen autores que introducen como esencial dentro del concepto de terrorismo el llamado elemento estructural, vale decir, para ellos este ilícito solo puede ser cometido por un grupo u organización con características terroristas.

Sin perjuicio de que en nuestra legislación el elemento estructural no haya sido considerado de lege data, como sí ha ocurrido en España, por ejemplo, podría suscitarse un eventual problema concursal entre el tipo penal de financiación y el de asociación ilícita terrorista, contenido en el artículo $2 \mathrm{~N}^{\circ} 5$ de la Ley $\mathrm{N}^{\circ} 18.314$. Esto, pues creemos que aquel que forma parte de una agrupación de este tipo deberá, necesariamente, solicitar, recaudar o proveer, directa o indirectamente, fondos, esto es, financiar de acuerdo con el artículo 8 de la Ley Antiterrorista, ya que dentro de la organización son sus propios miembros quienes deben velar por el "correcto" funcionamiento de la misma, realizando todas las gestiones tendientes a que ello ocurra.

En este caso estaremos frente a un concurso ideal de leyes penales entre el financiamiento y la asociación ilícita terrorista, debiendo aplicarse la pena mayor asignada al delito más grave. Para evitarlo estimamos que debería esclarecerse la posición del financista en la hipótesis de existir una asociación ilícita terrorista, en cuyo caso sostenemos que este debería situarse fuera de dicho grupo, como un extraneus, ya que su actuar se define más bien por un "hacer" que por un "estar". ${ }^{23}$

En cuanto al sujeto pasivo, hay que hacer una distinción. En primer lugar, si los fondos son efectivamente utilizados para la realización de un acto terrorista

\footnotetext{
23 Si bien Campo Moreno desarrolla su trabajo analizando el delito de colaboración con banda armada contemplado en las Secciones 1 y 2 del Capítulo VII del Título XXII del Libro II (artículos 571 a 576 y 578, principalmente) del Código Penal español (1995), creemos que los mismos argumentos pueden esgrimirse respecto del delito de financiamiento, ya que este tipo penal fue introducido recién en 2010 como artículo 576 bis. CAMPO (1997), p. 61. En sentido contrario vid. BLANCO (2009).
} 
concreto, el sujeto pasivo será, por una parte, aquella persona que directamente ha visto afectada su vida, integridad física o libertad, mientras que por la otra será el Estado. Ello, pues, como señaláramos, el terrorismo y su financiación afectan un bien jurídico de carácter dual.

En segundo lugar, en el caso de la mera solicitud sin entrega de fondos o en el caso de que esta se lleve a cabo, pero no se utilicen los aportes para llevar a cabo un atentado en particular, el sujeto pasivo será únicamente el Estado, como sujeto titular de los bienes jurídicos "seguridad pública" y "seguridad interior del Estado".

\section{ii. La conducta o acción típica}

En cuanto a la financiación del terrorismo se trata de un tipo penal alternativo desde el punto de vista de sus acciones típicas, ya que existen 3 modalidades para cometerlo. Al efecto, el artículo 8 señala que se sancionará a aquel que "por cualquier medio, directa o indirectamente, solicite, recaude o provea fondos...". Se trata, por tanto, de un delito simple o instantáneo, pues se perfecciona en un solo momento.

De acuerdo con el diccionario de la Real Academia Española, solicitar consiste básicamente en "pretender, pedir o buscar algo con diligencia y cuidado". Creemos que con este verbo rector se busca sancionar a aquellos que realizan gestiones tendientes a obtener el auspicio necesario para la realización de atentados terroristas, sin que sea necesaria una entrega real de fondos, ya que en ese caso estaríamos frente a una recaudación. Vale decir, se trata de un intermediario entre quien provee y aquel que recauda. Por lo mismo, estimamos que quien realiza la solicitud no tiene que ser la misma persona que aquella que recibe el aporte, ya que si así fuera estaríamos igualmente frente a un caso de recaudación.

La solicitud que sanciona el tipo penal del artículo 8 de la Ley Antiterrorista es, por ejemplo, la que tiene lugar cuando una persona en su círculo de influencia, por medio de sus contactos, obtiene patrocinadores para llevar a cabo delitos terroristas. Se trata en este caso de una labor lógica antes que material. Lo mismo ocurre en el caso de aquel que, sin solicitar expresamente fondos, "aconseja" a otro para que los aporte. En este caso se trataría de una solicitud indirecta de fondos.

En un comienzo este verbo rector no estaba contemplado en el proyecto de ley, situación que generó dos posturas claras. La primera opinión consistía en incorporar esta modalidad de comisión del delito. Sus partidarios señalaron que así se anticipaba la punibilidad en el caso de la recaudación, a fin de sancionarla 
aun si materialmente los dineros no llegaban a poder del recaudador, cubriendo aquellas hipótesis en que el solicitante era distinto de aquel que recaudaba. ${ }^{24}$

Por otro lado, estaban aquellos que señalaban la necesidad de no introducir esta forma verbal por considerar que la recaudación ya era un acto preparatorio de una forma de participación, cual es la financiación, por lo que la solicitud constituía una especie de tentativa de un acto preparatorio, que no resultaba admisible sancionar, más aún si se consideraba que la conducta se materializaría solamente con dicha petición en forma oral o escrita, aunque ella finalmente fuera rechazada. Se señaló que "la inclusión de esas formas verbales impiden la ocurrencia de actos preparatorios y 'adelantan' peligrosamente la consumación, extendiendo la sanción penal a límites intolerables". ${ }^{25}$

Nosotros compartimos esta segunda opinión, ya que creemos que la expresión "solicitar" no debió ser incluida en el artículo 8, pues con ella se adelanta de manera excesiva la barrera de protección penal, abarcando casos que, respecto de la recaudación, son perfectamente subsumibles en etapas previas del iter criminis y en otras figuras de participación, distintas de la del autor. Apoya lo anterior la profesora Myrna Villegas Díaz, quien señaló que la colaboración que debía sancionarse era aquella que se traducía en actos materiales y que tenía una finalidad próxima o inmediata, desligada de un acto delictivo concreto, por lo que "si se incluyera el vocablo 'solicitar' se estaría castigando un acto preparatorio que no dice relación con una verdadera aportación a la comisión de delitos de terrorismo". ${ }^{26}$

Finalmente, la Comisión Mixta optó por incorporar el verbo rector "solicitar", decisión apoyada por la Cámara de Diputados en discusión en Sala de 27 de agosto de 2003.

Respecto de las demás modalidades de la conducta típica, recaudar significa, entre otras cosas, "cobrar o percibir dinero". Aquí se requiere que los fondos queden efectivamente en poder del sujeto activo, quien debe guardarlos o mantenerlos en custodia a la espera de su utilización. No es requisito que haya sido él mismo quien gestionara su entrega, aunque esto es indiferente para la aplicación del tipo penal (si lo hizo se le sancionará por aplicación del artículo 8 en su modalidad de solicitud, mientras que en caso contrario se castigará por la recaudación). Se debe incluir en esta hipótesis, por ejemplo, a aquel que facilita su cuenta bancaria para recibir depósitos (aquel que los realiza será un proveedor, si los fondos son propios, o un coautor de la recaudación, si son ajenos).

Por su parte proveer consiste, principalmente, en "suministrar o facilitar lo necesario o conveniente para un fin". Con esta figura se sanciona al patrocinador,

\footnotetext{
${ }^{24}$ Historia de la Ley № 19.906, p. 67.

${ }^{25}$ Historia de la Ley No 19.906 , p. 69.

26 VILLEGAS (2006), p. 23.
} 
al que teniendo fondos decide aportarlos en la comisión de un delito terrorista, ya sea de motu propio o por solicitud de otra persona. Para que se configure esta modalidad, el sujeto activo debe permitir el acceso de los terceros a sus bienes, ya sea porque él mismo se los entrega (directamente) o porque permite que estos accedan a ellos sin oposición (indirectamente). Un ejemplo de esto último sería el caso en que el proveedor facilita las llaves de un depósito de armas para que los terroristas hagan uso de ellas en un atentado.

En cuanto a estos dos últimos supuestos de hecho, recaudar y proveer, no existió mayor discusión en cuanto a su procedencia, sin perjuicio de lo apuntado por Villegas Díaz, quien era partidaria de que el delito se configurara únicamente con la previsión de fondos, y no con la recaudación. Ello ya que el propio mensaje presidencial de la Ley $\mathrm{N}^{\circ} 19.906$ establecía que al que solo recaudara, pero no proveyera fondos, no podía caberle responsabilidad en ningún tipo de delito de terrorismo, lo que se vería reforzado por el sentido natural y obvio de la palabra recaudar. ${ }^{27}$

Sin perjuicio de la validez de esta última postura, consideramos que no es correcta ya que el argumento histórico en que se basa está sacado de contexto, pues lo que el mensaje señala no es que en el caso de la recaudación no se configurará un delito terrorista, sino que busca dejar de manifiesto que, en el caso de este verbo rector, el único ilícito terrorista que puede tener lugar es justamente el de financiación (y no otros delitos "determinados" de los señalados en el artículo 2 de la Ley Antiterrorista), por lo que en el caso de la recaudación no tendría aplicación la cláusula de subsidiaridad expresa de responsabilidad a que hemos aludido con anterioridad. ${ }^{28}$

Finalmente, la frase "por cualquier medio" y los adverbios "directa o indirectamente" indican que el financiamiento puede configurarse de múltiples formas, incluso por interpósita persona o mediante engaños o mentiras, por ejemplo.

Respecto de la acción o conducta típica, la Ley $\mathrm{N}^{0} 20.393$ no agrega elementos nuevos a propósito de las personas jurídicas y su responsabilidad penal, remitiéndose íntegramente al artículo 8 de la Ley Antiterrorista.

\footnotetext{
${ }^{27}$ Ibid.

${ }^{28}$ El párrafo completo del mensaje presidencial señala: "Para resolver el segundo aspecto [la recaudación previa de los fondos], se decidió ampliar el tipo autónomo propuesto también a la mera recaudación de los fondos para la comisión de delitos terroristas. Respecto de esta segunda forma comisiva, no rige la cláusula de subsidiariedad anteriormente aludida, precisamente porque de la aplicación de las normas generales se desprende que al que solo recauda pero no provee de fondos, no le puede caber responsabilidad en ningún delito terrorista determinado". Historia de la Ley No 19.906 , p. 6.
} 


\section{iii. Elementos subjetivos del tipo penal}

Como ya hemos adelantado a propósito del bien jurídico protegido, si tomamos en consideración lo dispuesto en el artículo 8 de la Ley $\mathrm{N}^{\circ} 18.314$ en relación con sus artículos 2 y 1, respectivamente, podemos afirmar que el delito de financiamiento del terrorismo contempla ciertos elementos subjetivos del tipo penal.

En primer término, el número 1 de esta última norma establece que el delito será terrorista cuando "se cometa con la finalidad de producir en la población o en una parte de ella el temor justificado de ser víctima de delitos de la misma especie, sea por la naturaleza y efectos de los medios empleados, sea por la evidencia de que obedece a un plan premeditado de atentar contra una categoría o grupo determinado de personas".

Por su parte, el numeral 2 señala como requisito "que el delito sea cometido para arrancar resoluciones de la autoridad o imponerle exigencias".

Estas finalidades alternativas exigidas por el artículo 1 de la Ley Antiterrorista, según Villegas Díaz, "constituyen elementos subjetivos de lo injusto y no un dolo específico". ${ }^{29}$

Respecto de estas pretensiones intencionales del agente, la profesora Villegas Díaz agrega que "son elementos subjetivos de tendencia interna intensificada, ya que basta con que el autor confiera a la acción típica un especial sentido subjetivo, sin que se exija un resultado en orden a que efectivamente el autor alcance sus propósitos". ${ }^{30}$

\section{d. Culpabilidad: el dolo y el error}

Respecto del financiamiento del terrorismo, podemos señalar que se trata de un delito que exige dolo directo, excluyéndose el dolo eventual, lo que se desprende del artículo 8 de la Ley $\mathrm{N}^{\circ} 18.314$, cuando señala que la solicitud, recaudación o provisión se sancionará en la medida que se realice con la "finalidad" de que los fondos se utilicen en la comisión de cualquiera de los delitos señalados en su artículo 2. Este concepto, el de "finalidad", engloba los dos elementos integradores del dolo, vale decir, el elemento intelectivo (el conocer) y el volitivo (el querer).

En el tipo penal que estamos analizando, el primero se presenta cuando el financista sabe que los fondos por él aportados serán utilizados para la comisión de algún delito sancionado por la ley como terrorista, situación que se ve reforzada por el hecho de que este ha sido efectivamente el resultado querido por

\footnotetext{
${ }^{29}$ VILLEGAS (2014), p. 14.

30 Íbid., pp. 14-15.
} 
aquel. Más específicamente, el elemento intelectivo abarca todas las circunstancias que integran la descripción del delito, aunque únicamente en sus rasgos esenciales, pues es imposible que el hombre común conozca todos los detalles de la realidad. En el caso del artículo 8 de la Ley $\mathrm{N}^{\circ} 18.314$ bastaría entonces, para castigar por este delito, que una persona supiera que está realizando una aportación a otro, quien hará uso de lo facilitado para la realización de actos terroristas.

En cuanto al elemento volitivo, el agente debe querer la realización del hecho típico y asumirlo como consecuencia de su comportamiento. Aquí se trata entonces de que el financista desee efectivamente subvencionar a una persona $u$ organización que él sabe se encarga de realizar actos terroristas.

En este mismo sentido se pronuncia Campo Moreno, quien señala que en este tipo de delitos siempre se exige que el sujeto tenga conocimiento del favorecimiento y de la finalidad perseguida por la organización. Ello, según el autor, da por supuesta "la estructura dolosa del delito, y por ende, la imposibilidad de su incriminación a título de culpa".

Ahora bien, quien desconoce las circunstancias concretas y el objeto de su acción actúa sin dolo. Este desconocimiento o falsa representación de los elementos del tipo penal se conoce como error de tipo. ${ }^{32}$ Este error recae sobre los elementos objetivos del tipo y afecta el elemento intelectual o cognitivo del dolo. Si quien actuó en error sobre un elemento del tipo no pudo prever ni evitar el resultado, esto es, le resultó invencible, su acción quedará impune. En caso contrario, o sea, si el error era vencible, podrá sancionársele a título de culpa en los casos excepcionales en que la ley admite esta figura.

Respecto de la financiación del terrorismo, podemos señalar como casos en que el error excluye el dolo cuando recae sobre la conducta típica aquel en que el financista se hace de los servicios de otro para proporcionar "indirectamente", esto es, interpósita persona, fondos para la comisión de delitos terroristas. Si aquel que hizo materialmente entrega de los fondos desconocía la finalidad con que serían utilizados y no tuvo forma de saberla, se encontrará actuando en error de tipo esencial invencible y, por tanto, su conducta será impune. Lo mismo ocurre en el caso de aquel que facilita los fondos a una persona u organización que aparentemente realiza actividades de caridad, por ejemplo, pero que tras esa fachada esconde propósitos delincuenciales de índole terrorista.

\footnotetext{
${ }^{31}$ CAMPO (1997), pp. 63-64.

32 Politoff (2004), p. 256.
} 


\section{e. Iter criminis, concursos y penalidad}

\section{i. Iter criminis}

En lo que respecta a la Ley Antiterrorista, solo su artículo 7 regula esta materia, estableciendo en el inciso primero que la tentativa debe ser sancionada con la pena mínima señalada por la ley para el delito consumado. Agrega el inciso segundo que la amenaza seria y verosímil de cometer el delito será castigada como tentativa del mismo.

Creemos que estas reglas son aplicables al ilícito de financiamiento del terrorismo por dos motivos, principalmente. En primer lugar, como señaláramos supra, se optó por incorporar este tipo penal en lugar del derogado artículo 8 y no en el inciso final del artículo 7 (que es el que se refiere al iter criminis), como originalmente se pretendió. Esto nos demuestra, por una parte, la importancia que nuestro legislador quiso darle al financiamiento del terrorismo, regulándolo autónomamente y no a propósito del iter criminis. Y, por otro lado, nos da cuenta de que si se hubiera querido introducir alguna regla especial a propósito de esta materia, dicho tipo penal habría sido regulado en el propio artículo 7 o, en caso contrario, se habría hecho referencia expresa a ello, lo que no ocurrió en el artículo 8.

En segundo término, en doctrina se distingue entre tentativa acabada e inacabada. La primera de ellas corresponde a lo que el Código Penal llama delito frustrado, mientras que la segunda se refiere a la simple tentativa. Como la ley habla en este artículo únicamente de la "tentativa", debemos entender que se aplica solo a la inacabada y, por lo tanto, no vemos inconveniente en la aplicación de estas normas al delito de financiamiento de actividades terroristas. Distinto sería si se tratara de la tentativa acabada, en cuyo caso no sería aplicable, ya que, al tratarse de un ilícito de mera actividad, no tiene cabida el delito frustrado.

Por último, el inciso final del artículo 7 indica que la conspiración en los delitos terroristas se castigará con la pena correspondiente al delito consumado, rebajada en uno o dos grados. Aquí se hace aplicación expresa de lo señalado en el inciso primero del artículo 8 del Código Penal, que establece que la conspiración solo es punible en los casos en que la ley la castiga especialmente. Debe tenerse presente, sin embargo, que el inciso final de esta última norma exime de toda pena por la conspiración en caso de desistimiento antes de principiar a poner el delito por obra y de iniciarse procedimiento judicial contra el culpable, con tal que el sujeto denuncie a la autoridad pública el plan y sus circunstancias. Nos parece que estas reglas igualmente son aplicables al delito de financiamiento.

En cuanto a la Ley $\mathrm{N}^{\circ} 20.393$ y la teoría del iter criminis, este cuerpo normativo no contiene disposiciones relativas al tema, por lo que entendemos que son aplicables las reglas especiales contenidas en la Ley $\mathrm{N}^{\circ} 18.314$ y las generales del Código Penal, siempre teniendo presente que la Ley $\mathrm{N}^{\circ} 20.393$ vino a 
introducir una excepción al principio societas delinquere non potest, con todas las restricciones que esto implica.

\section{ii. Concursos de delitos}

En cuanto a los concursos de delitos, este problema se suscitará toda vez que para la obtención de los "fondos" a los que hace referencia el mencionado artículo 8, el financista cometa otros delitos. ${ }^{33}$

Respecto de la Ley $\mathrm{N}^{\circ} 18.314$, su propio artículo 8 contiene una regla concursal en su "cláusula de subsidiariedad expresa" al señalar que la pena establecida para el delito de financiamiento del terrorismo no se aplicará al delincuente cuando "en virtud de la provisión de fondos le quepa responsabilidad en un delito determinado, caso en el cual se le sancionará por este último título, sin perjuicio de lo dispuesto en el artículo 294 bis del Código Penal".

Hay que precisar que esta norma sólo es aplicable en caso de provisión de fondos y no tratándose de solicitud ni recaudación. Ello, pues, así se establece expresamente, aplicándose para los demás casos las reglas generales en materia de concursos.

Así, en el caso de la solicitud, si existe conexión ideológica entre la financiación (mediante su modus operandi consistente en solicitar, reiteramos) y otro delito, creemos que nos encontraremos frente a un concurso medial, debiendo aplicarse, de acuerdo con el artículo 75 del Código Penal, la pena mayor asignada al delito más grave.

En cuanto a la recaudación, pensamos que se está frente a un concurso aparente de leyes penales, el que puede solucionarse mediante la aplicación del principio de consunción, ya que se estaría frente a actos posteriores copenados: quien hurta, roba, secuestra, trafica drogas o comete cualquier otro delito, con la intención de recaudar fondos para aportarlos a la comisión de un ilícito terrorista, no está haciendo más que aprovechándose de los efectos del primero para cometer un segundo delito.

En este último caso debe aplicarse la pena correspondiente al delito de mayor intensidad, esto es, aquella correspondiente al financiamiento del terrorismo.

\footnotetext{
${ }^{33}$ Las hipótesis son innumerables. Tal es el caso de aquel que, para proporcionar financiamiento a otro para que se cometa alguno de los delitos señalados en el artículo 2 de la Ley No 18.314, roba o hurta dineros, armamento o cualquier otro elemento que pudiera considerarse incluido dentro del concepto de "fondos"; secuestra a una persona para cobrar una recompensa que será destinada a solventar dichas actividades; trafica sustancias prohibidas con el mismo objeto; incurre en estafas únicas o reiteradas, etcétera.
} 
En cambio, como ya se indicó, en el caso del financiamiento del terrorismo en su modalidad de provisión de fondos, el legislador ha optado por la subsidiariedad del delito, ya que, de acuerdo con la cláusula antes mencionada, solo será sancionado como tal cuando el hecho no constituya a la vez otro ilícito.

Además, debe señalarse que la financiación mediante la provisión de fondos es subsidiaria respecto de cualquier otro ilícito y no solo de aquellos contenidos en la Ley Antiterrorista. Así nos parece que se extrae de la referencia que la propia cláusula realiza respecto del artículo 294 bis del Código Penal, que se refiere a las penas aplicables a los integrantes de asociaciones ilícitas, las que pueden o no tener el carácter de terroristas.

En cuanto a las personas jurídicas, la Ley $\mathrm{N}^{\circ} 20.393$ no hace referencia a los concursos, siendo aplicables las normas que a propósito de la materia contiene el Libro I del Código Penal, teniendo presente siempre que aquellas responden penalmente solo por un catálogo limitado de delitos. Paradigmático nos parece el caso de aquella persona jurídica que incurre en el delito de lavado de activos para ocultar el origen ilícito de los dineros que aportará a una organización terrorista.

\section{iii. Penalidad}

Tanto la Ley $\mathrm{N}^{\circ} 18.314$ como la $\mathrm{N}^{\mathrm{o}} 20.393$ regulan específicamente el tema de las penas aplicables en caso del delito de financiamiento, por lo que debemos estarnos a estas normas.

Así es como el artículo 8 de la Ley Antiterrorista señala que la pena aplicable al financista será la de presidio menor en sus grados mínimo a medio, o sea, de 61 días a 3 años, a menos que en virtud de la provisión de fondos le quepa responsabilidad en un delito determinado, caso en el que se le sancionará por este último título, sin perjuicio de lo dispuesto en el artículo 294 bis del Código Penal, que se refiere específicamente al caso de la asociación ilícita.

Por su parte, la Ley $\mathrm{N}^{\circ} 20.393$ regula la materia en el Título II, que se denomina "Consecuencias de la declaración de responsabilidad penal de la persona jurídica". Al efecto, el artículo 15 señala que al delito de financiamiento del terrorismo se le aplicará las penas previstas para los simples delitos, las que, según el artículo 14, consisten en la prohibición temporal de celebrar actos y contratos con organismos del Estado en su grado mínimo a medio, es decir, de 2 a 4 años; la pérdida de beneficios fiscales en su grado mínimo a medio (20 al 70 por ciento del beneficio fiscal) o la prohibición absoluta de recepción de los mismos de dos a tres años; y la multa en su grado mínimo a medio (desde 200 a 10.000 unidades tributarias mensuales). 
En estos casos, según el inciso final del artículo 14, siempre serán aplicables las penas accesorias señaladas en el artículo $13 .^{34}$

Por último, los artículos 16 y 17 se refieren a la determinación de la pena en caso de concurrir circunstancias modificatorias de responsabilidad penal y a las reglas de determinación judicial de la pena, respectivamente.

\section{f. Circunstancias modificatorias de responsabilidad penal}

Sin perjuicio de la aplicación supletoria de las normas del Código Penal relativas a esta materia, específicamente los artículos 11 y 12 , que se refieren a las circunstancias atenuantes y agravantes, respectivamente, la Ley $\mathrm{N}^{\circ} 18.314$ contiene una disposición de aplicación específica.

Así es como su artículo 4 se refiere a una única circunstancia modificatoria, particularmente una atenuante que permite disminuir la pena hasta en dos grados a aquel que lleva a cabo acciones tendientes a evitar o aminorar las consecuencias del hecho incriminado, o da informaciones o proporciona antecedentes que sirven efectivamente para impedir o prevenir la perpetración de otros delitos terroristas, o bien para detener o individualizar a los responsables de esta clase de delitos.

Creemos que esta atenuante debe aplicarse al financista que lleva a cabo alguna de las acciones que describe la norma como una forma de soslayar las consecuencias dañinas de su propio delito, atendida la ubicación del artículo 4 que lo convierte en una norma de carácter general respecto de la Ley $\mathrm{N}^{\circ} 18.314$ y, principalmente, porque dicha norma no se circunscribe únicamente a los delitos mencionados en el artículo 2.

Por su parte, la Ley $\mathrm{N}^{0} 20.393$ establece tanto circunstancias atenuantes como agravantes. Respecto de las primeras, el artículo 6 señala en sus números 1 y 2 que se aplican aquellas descritas en los números 7 y 9 del artículo 11 del Código Penal, o sea, se disminuirá la responsabilidad penal a aquella persona jurídica que procure con celo reparar el mal causado o impedir sus ulteriores perniciosas consecuencias y a aquella que colabore sustancialmente al esclarecimiento de los hechos. ${ }^{35}$ A contrario sensu, las demás atenuantes enumeradas en el artículo 11 no

\footnotetext{
${ }^{34} \mathrm{El}$ artículo 13 señala como penas accesorias la publicación de un extracto de la sentencia a costa de la persona jurídica sancionada, el comiso del producto del delito y demás efectos del mismo, y en el caso de que el delito cometido suponga la inversión de recursos de la persona jurídica superiores a los ingresos que ella genera, se impondrá como pena accesoria el entero en arcas fiscales de una cantidad equivalente a la inversión realizada.

$35 \mathrm{El}$ número 2 del artículo 6 señala que "se entenderá especialmente que la persona jurídica colabora sustancialmente cuando, en cualquier estado de la investigación o del procedimiento judicial, sus representantes legales hayan puesto, antes de conocer que el procedimiento judicial se dirige contra ella, el hecho punible en conocimiento de las autoridades o aportado antecedentes para establecer los hechos investigados".
} 
son aplicables respecto de las personas jurídicas. Agrega el número 3 del artículo 6 que la adopción por parte de la persona jurídica, antes del comienzo del juicio, de medidas eficaces para prevenir la reiteración de la misma clase de delitos objeto de la investigación también constituye una atenuante.

Por último, el artículo 7 se refiere a una única circunstancia agravante, cual es haber sido condenada, la persona jurídica, dentro de los cinco años anteriores por el mismo delito.

\section{Resumen}

El "financiamiento" de actividades terroristas es una actividad compleja, comprensiva no solo de las contribuciones en dinero que se realizan a este tipo de organizaciones, sino que también de toda clase de aportaciones, de diversa índole, provenientes de las más variadas fuentes, lícitas e ilícitas, que permitan a los terroristas realizar ilícitos de esta naturaleza.

En nuestro país, este tipo penal está regulado en dos normas especiales: el artículo 8 de la Ley $\mathrm{N}^{\circ} 18.314$ y la Ley $\mathrm{N}^{\circ} 20.393$, norma, esta última, que establece la responsabilidad penal de las personas jurídicas por el financiamiento del terrorismo, entre otros delitos, remitiéndose para ello al propio artículo 8 de la Ley Antiterrorista y estableciendo ciertas normas especiales fundamentalmente a propósito de la determinación de la responsabilidad penal y de las sanciones.

Por su parte, el artículo 8 de la Ley $\mathrm{N}^{\circ} 18.314$ vino a llenar el vacío que existía en nuestra legislación, en la cual en principio solo era punible el apoyo a la ejecución de un delito terrorista determinado o bien la provisión de fondos a una asociación ilícita de esa clase, requiriéndose en ambos casos de un aporte efectivo. Su inclusión obedece a la suscripción por parte de Chile de una serie de instrumentos internacionales relativos a la materia.

Con la inserción de este artículo 8 se hizo posible la sanción de conductas previas, sin exigirse la entrega efectiva de los fondos ni la realización de un delito concreto. Ello queda de manifiesto especialmente en el caso de la "solicitud" y de la "recaudación". Esta es una de las principales críticas que se le realiza a este tipo penal, ya que con la inclusión de estas acciones típicas se produce un adelantamiento de la barrera de protección, que para algunos autores es considerado como excesivo.

La regulación que nuestro derecho realiza del delito de financiamiento del terrorismo lo sitúa como un delito de mera actividad, sin perjuicio de que esta caracterización haya sido objeto de múltiples discusiones tanto en el Parlamento como posteriormente en doctrina. Está constituido por una sucesión de actos netamente preparatorios, que no entran en la esfera de ejecución del delito y respecto de los cuales el legislador ha anticipado su punición debido a la 
importancia de los bienes jurídicos protegidos, cuales son, con carácter singular, vida, integridad física y libertad, y con carácter colectivo, seguridad pública y seguridad interior del Estado.

Se trata de un tipo penal alternativo desde el punto de vista de sus acciones típicas, ya que puede ser cometido, como dijimos, solicitando o recaudando fondos, pero además proveyéndolos. Todas estas conductas pueden llevarse a cabo por cualquier medio, directa o indirectamente. Sin embargo, sea cual sea la modalidad, siempre se exige dolo directo, pues la acción típica debe realizarse con la "finalidad" de que el aporte se utilice para la comisión de un delito terrorista.

Es un delito de sujeto activo indiferenciado, es decir, puede ser cometido por cualquier persona natural siempre y cuando esta sea una distinta de aquella que materialmente realiza los actos terroristas. En el caso de las personas jurídicas, solo pueden ser responsables de este delito aquellas expresamente señaladas en el artículo 3 de la Ley $\mathrm{N}^{\circ} 20.393$, vale decir, la excepción al principio societas delinquere non potest no es absoluta, sino limitada.

Por último, en lo relativo al sujeto pasivo, hay que distinguir si los fondos fueron o no utilizados efectivamente para la realización de un acto terrorista concreto. En el primer caso, el ofendido será, por una parte, aquel directamente afectado en su vida, integridad física o libertad y, por la otra, el Estado. En caso contrario, sujeto pasivo será únicamente este último, como titular de los bienes jurídicos "seguridad pública" y "seguridad interior del Estado". 
Plaza - Análisis dogmático-penal del delito de financiamiento del terrorismo

\section{BIBLIOGRAFÍA}

* Blanco Cordero, Isidoro: “¿Es necesario tipificar el delito de financiación del terrorismo en el Código Penal español?”, Athena Intelligence Journal, Vol. 4, No 1, 2009.

* Bullemore Gallardo, Vivian: Curso de Derecho penal, Editorial LexisNexis, Tomo II, 1a edición, Santiago, 2005.

* CAMpo Moreno, Juan Carlos: Represión penal del terrorismo: Una visión jurisprudencial, General de Derecho, S. L., Valencia, 1997.

* Convenio Internacional para la Represión de la Financiación del Terrorismo. <http://www.acnur.org/t3/fileadmin/scripts/doc.php?file=biblioteca/pdf/ 1636> [Consultado el 22 de junio de 2014].

* Del BARRIo Reyna, Álvaro y LEÓN Reyes, José: Terrorismo, ley antiterrorista y derechos bumanos, Universidad Academia de Humanismo Cristiano, Santiago, 1991.

* Historia de la Ley $\mathrm{N}^{\circ} 19.027$, que modifica la Ley $\mathrm{N}^{\circ} 18.314$, que determina conductas terroristas y fija su penalidad, p. 5 [En línea] <http://bcn.cl/19a83> [Consultado el 22 de junio de 2014].

* Lastra López, Daniela y ANDuEza Quezada, Danilo: El tratamiento del lavado de dinero en Chile ante la normativa de la Ley $N^{\circ}$ 19.913, Editorial Metropolitana, Santiago, 2009.

* Mensaje de S. E. el Presidente de la República de 2 de octubre de 2002. Historia de la Ley $\mathrm{N}^{\mathrm{o}} 19.906$, que modifica la Ley $\mathrm{N}^{\mathrm{0}} 18.314$, que determina conductas terroristas y fija su penalidad, en orden a sancionar más eficazmente la financiación del Terrorismo, en conformidad a lo dispuesto por el Convenio Internacional para la Represión de la Financiación del Terrorismo, p. 6 [En línea] <http://bcn.cl/5he2> [Consultado el 22 de junio de 2014].

* Politoff, Sergio, MATUS, Jean Pierre y RAmírez, María Cecilia: Lecciones de Derecho penal chileno. Parte general, Editorial Jurídica de Chile, 2a edición actualizada, Santiago, 2004.

* Shelly, Louise: "El financiamiento del terrorismo", Revista de Análisis Jurídico Urbe et Ius, $\mathrm{N}^{\circ}$ 4, Asociación Civil Urbe et Ius, Buenos Aires, 2005. [En línea] $<$ http://www.urbeetius.org/images/newsletters/04/news4_terrorismo.pdf $>$ [Consulta: 22 de junio de 2014]

* Villegas Díaz, Myrna: Terrorismo: Un problema de estado. Tratamiento jurídico en la legislación comparada. Especial referencia a los delitos de terrorismo en las legislaciones de Chile y España. Tesis doctoral [inédita], Área Penal, Departamento de Derecho público, Universidad de Salamanca, 2001.

"Terrorismo: ¿Crimen organizado? Análisis comparado", Anales de la Facultad de Derecho, No 1, Universidad de Chile, 2004.

"Los delitos de terrorismo en el Anteproyecto de Código Penal", Revista Política Criminal, Vol. 1, No 2, Centro de Estudios de Derecho penal, Universidad de Talca, 2006. [En línea] <http://www.politicacriminal.cl/n_02/a_3_2.pdf > [Consulta: 22 de junio de 2014]. 